\title{
Outcome of HIV-associated lymphoma in a resource-limited setting of Jos, Nigeria
}

Olugbenga Akindele Silas ${ }^{1 *}$, Chad J. Achenbach², Lifang Hou², Robert L. Murphy², Julie O. Egesie², Solomon A. Sagay ${ }^{4}$, Oche O. Agbaji ${ }^{5}$, Patricia E. Agaba6, Jonah Musa ${ }^{4}$, Agabus N. Manasseh', Ezra D. Jatau ${ }^{3}$, Ayuba M. Dauda', Maxwell O. Akanbi ${ }^{5}$ and Barnabas M. Mandong ${ }^{1}$

\begin{abstract}
Background: Lymphoma is a leading cause of cancer-related death among human immunodeficiency virus (HIV)infected individuals in the current era of potent anti-retroviral therapy (ART). Globally, mortality after HIV-associated lymphoma has profound regional variation. Little is known about HIV-associated lymphoma mortality in Nigeria and other resource-limited setting in sub-Saharan Africa. Therefore, we evaluated the all-cause mortality after lymphoma and associated risk factors including HIV at the Jos University Teaching Hospital (JUTH) Nigeria.

Methods: We conducted a ten-year retrospective cohort study of lymphoma patients managed in JUTH. The main outcome measured was all-cause mortality and HIV infection was the main exposure variable. Overall death rate was estimated using the total number of death events and cumulative follow up time from lymphoma diagnosis to death. Cox proportional hazard regression was used to assess factors associated with mortality after lymphoma diagnosis.

Results: Out of 40 lymphoma patients evaluated, 8(20.0\%) were HIV positive and 32(80.0\%) were HIV negative. After 127.63 person- years of follow-up, there were 16 deaths leading to a crude mortality rate of 40.0 per 100 person-years. The 2-year probability of survival was 30\% for HIV-infected patients and 74\% for HIV-uninfected. Median survival probability for HIV-infected patients was 2.1 years and 7.6 years for those without HIV. Unadjusted hazard of death was associated with late stage, HR $11.33(95 \% \mathrm{Cl} 2.55,50.26, p=0.001)$; low cumulative cycles of chemotherapy, HR 6.43(95\% $\mathrm{Cl} 1.80,22.89, p=0.004)$; greater age, HR 5.12(95\% Cl 1.45,18.08,p = 0.01); presence of comorbidity, HR 3.43(95\% Cl 1. $10,10.78, p=0.03)$; and HIV-infection, HR $3.32(95 \% \mathrm{Cl} 1.05,10.51, p=0.04)$. In an adjusted model only stage was significantly associated with death, AHR 5.45(1.14-26.06, $p=0.03)$.

Conclusion: Our findings suggest that HIV- infection accounted for three times probability of death in lymphoma patients compared to their HIV-uninfected counterparts due to late stage of lymphoma presentation in this population. Also initiation of chemotherapy was associated with lower probability of death among lymphoma patients managed at JUTH, Nigeria. Earlier stage at lymphoma diagnosis and prompt therapeutic intervention is likely to improve survival in these patients. Future research should undertake collaborative studies to obtain comprehensive regional data and identify unique risk factors of poor outcomes among HIV-infected patients with lymphoma in Nigeria.
\end{abstract}

Keywords: Human immunodeficiency virus, Mortality, Lymphoma, Outcomes, Nigeria

\footnotetext{
* Correspondence: drgbenga@yahoo.com

${ }^{1}$ Pathology Department, Faculty of Medical Sciences, University of Jos/Jos

University Teaching Hospital, Jos, Plateau State, Nigeria

Full list of author information is available at the end of the article
}

(c) The Author(s). 2017 Open Access This article is distributed under the terms of the Creative Commons Attribution 4.0 International License (http://creativecommons.org/licenses/by/4.0/), which permits unrestricted use, distribution, and reproduction in any medium, provided you give appropriate credit to the original author(s) and the source, provide a link to the Creative Commons license, and indicate if changes were made. The Creative Commons Public Domain Dedication waiver (http://creativecommons.org/publicdomain/zero/1.0/) applies to the data made available in this article, unless otherwise stated. 


\section{Background}

Lymphoma accounts for approximately 3\% (non-Hodgkin) and $0.5 \%$ (Hodgkin) of all cancers worldwide [1-3]. HIVinfected individuals experience lymphoma rates 5-15 times higher than those without HIV, even in the modern era of potent antiretroviral therapy (ART) [4-8]. According to global information and advice on HIV/AIDS (AVERT) 2015, of all people living with HIV globally 9\% live in Nigeria and account for 14\% of global AIDS-related deaths [3]. In Nigeria, the prevalence of HIV-infected individuals diagnosed with lymphomas increased from $2.3 \%$ in 2009 to $4.3 \%$ in 2010 [8].

Survival outcomes reported for HIV-lymphomas worldwide are conflicting and few. While a few studies state equal health outcomes comparable to HIVuninfected lymphoma patients, most studies report poor 2 years survival outcomes with wide ranges between 24.4 and $71.7 \%$ for HIV-infected lymphoma from the US and Europe. This variability in mortality outcomes could be due to differences in demographic or disease factors such as age, stage, co-morbidities or histology [7-30]. The effect of disease specific factors such as stage of lymphoma, presence of cumulative number of cycles of chemotherapy received and proper use of antiretroviral (ART) drug use in this setting are unclear [31-33]. Thus this study aims to assess the contributory factors to mortality unique to Nigeria.

\section{Methods}

\section{Study setting and design}

We conducted a 10-year retrospective cohort study from January 1, 2005 to March 31, 2015 of adult lymphoma patients seen at the Jos University Teaching Hospital (JUTH) in Jos, north central Nigeria. Patients were followed up to determine their patient time contribution from the beginning of the study (time of initiation of chemotherapy for lymphoma) to occurrence of the primary outcome (death) or the end of study period. Those lost to follow-up were censored at data of their last known follow-up in clinic.

\section{Inclusion criteria}

We included all adult (18 \pm years of age) patients diagnosed with lymphoma and managed at JUTH from January 1, 2005 to March 31, 2015.

\section{Exclusion criteria}

We excluded adults with treatment, follow-up, and care for lymphoma obtained outside of JUTH. We also excluded lymphoma patients who were pregnant.

\section{Data collection}

Demographic variables (age, sex), clinical variables (comorbidity, HIV sero-status, stage, subtype, chemotherapy cycles), laboratory variables (CD4+ T cell count, HIV RNA level), follow up and outcome(mortality) data for the HIV-positive lymphoma group were obtained from the electronic records of the AIDS Prevention Initiative in Nigeria (APIN) center of JUTH. Data for the HIVnegative group were obtained from the case report forms from the Hematology department and electronic database of the Pathology department of JUTH. Other sources of data were the inpatient notes, hospital discharge summaries, mortuary records, and from phone calls to patients or their relatives.

\section{Demographic variables measured}

Sex was either male or female, age was analyzed as continuous variable.

\section{Clinical variables measured}

The primary outcome variable was all-cause mortality (determined as below), and the main exposure variable was HIV infection (by HIV antibody testing). Other variables measured were cumulative cycles of chemotherapy received within a year after lymphoma diagnosis, baseline CD4+ T cell count, baseline HIV RNA level, comorbidities, tumor stage, histologic tumor type and ART use. Baseline nadir CD4+ T cell count was the lowest value before or at initiation of ART and baseline HIV RNA level was the peak level before or at initiation of ART. Information on mortality was obtained from hospital records, mortuary death records and telephone interview with family of patient. Histologic tumor type was based on hematoxylin and eosin stain microscopic pathology report and divided into non-Hodgkin lymphoma (NHL) and Hodgkin lymphoma (HL) according to the W.H.O 2008 classification of lymphoma [Appendix B]. Tumor stage at lymphoma diagnosis was according to Ann Arbor staging with stages I and II (early stage), stages III and IV (late stage) [Appendix A]. Time from lymphoma diagnosis to death was calculated in days and subsequently converted to lunar months and years. Comorbidities were other illnesses recorded for the patients other than lymphoma and HIV infection. Cumulative cycles of chemotherapy was calculated as the total cycles of chemotherapy received by each patient within the first year after lymphoma diagnosis. Patients were considered to be on ART if they had been receiving any combination ART at least 3 months before initiation of lymphoma chemotherapy. Clinically relevant cut-off levels for binary variables $\mathrm{CD} 4+\mathrm{T}$ cell count and HIV RNA levels were $200 \mathrm{cell} / \mu \mathrm{l}$ and 400 copies $/ \mathrm{ml}$ respectively.

\section{Statistical analysis}

The analytical focus of this study was to determine allcause probability of death and to identify likely risk factors that contribute to death in lymphoma patients in this low 
resource setting. The overall mortality rate was estimated using total number of death events and the cumulative person time follow-up from initiation of chemotherapy to death. Differences in proportions and means between the HIV-infected and HIV-uninfected patients was assessed using Chi-square or Fisher's exact tests for proportions and t-test for mean. Mean and standard deviations for baseline HIV RNA levels were log transformed for easy interpretation. Cox proportional hazard analysis (unadjusted) was used to examine the association between all-cause mortality in the lymphoma patients and variables age, sex, stage, histologic subtype, cumulative cycles of chemotherapy used, comorbidity and HIV infection. Adjusted analysis was then conducted. $P$ value $<0.05$ was considered significant and only those having significant $p$ values were used in the adjusted model. A further analysis was done for the HIV-associated lymphoma group using Chi-square or Fisher's where applicable for categorical variables and student t-test for means of continuous variables. All statistical tests were 2-sided with type 1 error set at 0.05 for statistical significance. Sex, age, cumulative cycles of chemotherapy, HIV-status, comorbidities, stage, histologic tumor subtype, baseline CD4+ T cell count and baseline HIV RNA level were all treated as binary variables for determining predictors of death and for the further analysis of the HIV group respectively. To estimate the hazard of death following lymphoma diagnosis, we used time from diagnosis in years as time covariate and death as failure event. Kaplan-Meier graph estimating probability of survival following lymphoma diagnosis by HIV status was plotted. We used Log-rank test to test for difference in probability of survival between the HIV positive and HIV negative lymphoma groups with $p$-value 0.05 signifying significant difference in survival. Statistical analysis was performed with STATA version 11.0 college station, Texas, USA.

\section{Results}

\section{Demographic data}

Forty lymphoma patients were identified and followed for a total of 127.63 person-years. Participants comprised $15(37.5 \%)$ women and $25(62.5 \%)$ men [Table 1].

\section{Clinical data}

Non-Hodgkin lymphoma was the dominant histologic subtype $(87.5 \%)$. Of the 8 HIV-positive patients, $6(75.0 \%)$ presented with late stages III and IV lesions while of the 32 HIV- negative patients 22(68.8\%) presented with early stages I and II lesions. Also, the majority of patients $(60.0 \%)$ received more than four cumulative cycles of chemotherapy. Only 16 (40.0\%) patients presented with additional comorbid disease, $p=0.33$. Comorbidities were mainly hepatitis $\mathrm{B}$, hepatitis C and Kaposi sarcoma. Overall 16/40
Table 1 A bivariate analysis of demographic/clinical characteristics of lymphoma patients seen at Jos University Teaching Hospital from 01/01/2005 to 03/30/2015 by HIV status

\begin{tabular}{|c|c|c|c|c|}
\hline & $\begin{array}{l}\text { HIV Negative } \\
\mathrm{N}(\%)\end{array}$ & $\begin{array}{l}\text { HIV Positive } \\
\mathrm{N}(\%)\end{array}$ & $\begin{array}{l}\text { Overall } \\
\mathrm{N}(\%)\end{array}$ & $P$-value \\
\hline Number & $32(80.0)$ & $8(20.0)$ & $40(100.0)$ & \\
\hline \multicolumn{5}{|l|}{ Gender, n (\%) } \\
\hline Male & $19(59.4)$ & $6(75.0)$ & $25(62.5)$ & \multirow[t]{2}{*}{0.41} \\
\hline Female & $13(40.6)$ & $2(25.0)$ & $15(37.5)$ & \\
\hline \multicolumn{5}{|l|}{ Age(yrs) } \\
\hline$\leq 40$ & $18(56.3)$ & $2(25.0)$ & $20(50.0)$ & \multirow[t]{2}{*}{0.11} \\
\hline$>40$ & $14(43.8)$ & $6(75.0)$ & $20(50.0)$ & \\
\hline Age (Mean, SD) yrs & $39.78,15.27$ & $46.38,11.46$ & & 0.20 \\
\hline \multicolumn{5}{|l|}{ Histologic sub-type } \\
\hline $\mathrm{NHL}$ & $28(87.5)$ & $7(87.5)$ & 35 (87.5) & \multirow[t]{2}{*}{1.00} \\
\hline $\mathrm{HL}$ & $4(12.5)$ & $1(12.5)$ & $5(12.5)$ & \\
\hline \multicolumn{5}{|l|}{ Stage } \\
\hline$|\&| \mid$ & $22(68.8)$ & $2(25.0)$ & $24(60.0)$ & \multirow[t]{2}{*}{0.02} \\
\hline III \& IV & $10(31.3)$ & $6(75.0)$ & $16(40.0)$ & \\
\hline \multicolumn{5}{|l|}{ Chemotherapy cycles } \\
\hline$>4$ & $21(65.6)$ & $3(37.5)$ & $24(60.0)$ & \multirow[t]{2}{*}{0.15} \\
\hline$\leq 4$ & $11(34.4)$ & $5(62.5)$ & $16(40.0)$ & \\
\hline \multicolumn{5}{|l|}{ Comorbidity } \\
\hline Absent & $18(56.3)$ & $6(75.0)$ & $24(60.0)$ & \multirow[t]{2}{*}{0.33} \\
\hline Present & $14(43.8)$ & $2(25.0)$ & $16(40.0)$ & \\
\hline \multicolumn{5}{|l|}{ Mortality (death) } \\
\hline No deaths & $21(65.6)$ & $3(37.5)$ & $24(60.0)$ & \multirow[t]{3}{*}{0.15} \\
\hline Deaths & $11(34.4)$ & $5(62.5)$ & $16(40.0)$ & \\
\hline $\begin{array}{l}\text { Total Person years } \\
\text { follow up }\end{array}$ & 10.85 & 116.78 & 127.63 & \\
\hline $\begin{array}{l}\text { Number of loss to } \\
\text { Follow up }\end{array}$ & 2 & 0 & & \\
\hline
\end{tabular}

NHL non-Hodgkin lymphoma, HIV human Immune deficiency virus; Comorbidity e.g. hepatitis, tuberculosis, other cancers. Deaths (all-cause mortality); no death (loss to follow up/alive at end of study)

(40.0\%) of the lymphoma patients died. A total of $2 /$ $40(5.0 \%)$ of the lymphoma patients were lost to follow up during the period of study and they were all HIV negative. A total of $8 / 40(20.0 \%)$ patients were HIV positive and 32/40 (80.0\%) were HIV negative. Among those with HIV-associated lymphoma, $75 \%$ were male, $6 / 8(75 \%)$ had late stage presentation (stage III \& IV) and 5/8 (62.5\%) died. Mean age of HIV-positive patients was higher at 46 years compared to 40 years for the HIV-negative. No other factors were associated with HIV status [Table 1].

Eighty percent of the HIV-associated lymphoma patients who died had baseline CD4+ T cell counts $\leq 200$ cells $/ \mu \mathrm{l}(p=0.03)$. 


\section{Unadjusted Cox model}

In the unadjusted model, mortality was associated with higher age, HR 5.12 ( $p=0.01$, CI 1.45-18.08), late stage, HR 11.33 ( $p=0.001$, CI 2.55-50.26), low cumulative cycles of chemotherapy, HR $6.43(p=0.004$, CI 1.80 $22.89)$, presence of comorbidities, HR $3.43(p=0.03$, CI $1.10-10.78)$ and HIV-infection, HR 3.32( $p=0.04, \mathrm{CI}$ 1.05-10.51) [Table 2].

\section{Adjusted Cox model}

In the adjusted model including HIV status, stage of lymphoma, age and number of chemotherapy cycles received, the only statistically significant factor associated with death was late stage of lymphoma (AHR 5.45( $p=0.034$, CI 1.14-26.06) [Table 2].

\section{Kaplan-Meier survival graph}

The log-rank test for Kaplan-Meier graph were significantly different between those with and without HIV infection $(P=0.03)$. Median survival probability for HIV-infected group was 2.1 years while for HIVuninfected group was 7.6 years. The 2-year survival probability after lymphoma diagnosis was 30\% for HIV-infected and 74\% for HIV-uninfected lymphoma patients $(p=0.012)$ [Fig. 1].

\section{Discussion}

In this 10-year retrospective cohort study, mortality was higher (62.5\%) among the HIV-positive group as most of them $(75.0 \%)$ presented at late stages II and III [Table 1]. Late stage presentation at diagnosis amongst HIVlymphoma patients was also reported in a similar study in Uganda by Bateganya et al. [31]. Only the stage of lymphoma at diagnosis was significantly associated with death after adjusting for HIV-status, stage, age and number of chemotherapy cycles received. In a similar 4-year retrospective study of 154 NHL patients by Bateganya et al., the same factors used in our study's adjusted model were all significant in predicting death specifically in HIVinfected NHL patients not on ART [31]. But a similar study in the USA by Gopal et al. in a large cohort of NHL patients, showed only older age and HIV viremia to be predictive of survival [26]. Small sample size of lymphoma patients in this study could have accounted for stage being the only significant factor predictive of death.

Most HIV-infected patients (62\%) in this study received lower cumulative cycles of chemotherapy $(<4 \mathrm{cy}-$ cles) within a year after initiation of lymphoma treatment. This could be due to inability to purchase chemotherapy drugs as this competes with other drugs the patients need to buy. Also is the fact that they have

Table 2 Unadjusted and Adjusted analysis of characteristics of lymphoma patients using cox- proportional hazards

\begin{tabular}{|c|c|c|c|c|}
\hline & $\begin{array}{l}\text { Unadjusted model } \\
\text { HR }(96 \% \mathrm{Cl})\end{array}$ & $P$-Value & $\begin{array}{l}\text { Adjusted model } \\
\text { HR }(95 \% \mathrm{Cl})\end{array}$ & $P$-Value \\
\hline \multicolumn{5}{|l|}{ Gender } \\
\hline Male(referent) & & 0.46 & & \\
\hline Female & $1.49(0.51-4.39)$ & & & \\
\hline \multicolumn{5}{|l|}{ Age(years) } \\
\hline$\leq 40$ (referent) & & & & 0.16 \\
\hline$>40$ & $5.12(1.45-18.08)$ & 0.01 & $1.04(0.98-1.10)$ & \\
\hline \multicolumn{5}{|l|}{ Histologic subtype } \\
\hline $\mathrm{HL}($ referent) & & 0.99 & & \\
\hline $\mathrm{NHL}$ & $1.01(0.23-4.52)$ & & & \\
\hline \multicolumn{5}{|l|}{ Stage } \\
\hline | \& ||(referent) & & 0.001 & & 0.03 \\
\hline III \& IV & $11.33(2.55-50.26)$ & & $5.45(1.14-26.06)$ & \\
\hline \multicolumn{5}{|l|}{ Chemotherapy cycles } \\
\hline$>4$ (referent) & & 0.004 & & 0.21 \\
\hline$\leq 4$ & $6.43(1.80-22.89)$ & & $2.40(0.61-9.25)$ & \\
\hline \multicolumn{5}{|l|}{ Comorbidity } \\
\hline Absent(referent) & & 0.03 & & \\
\hline Present & $3.43(1.10-10.78)$ & & & \\
\hline \multicolumn{5}{|l|}{ HIV serostatus } \\
\hline Negative(referent) & & 0.04 & & 0.56 \\
\hline Positive & $3.32(1.05-10.51)$ & & $1.49(0.42-5.01)$ & \\
\hline
\end{tabular}




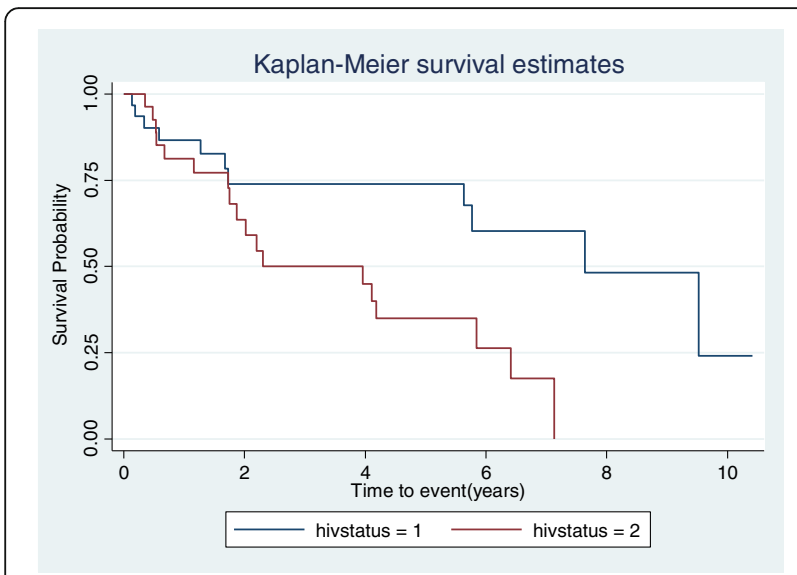

Fig. 1 Kaplan Meier estimation of survival stratified by HIV status $(H I V$ positive $=$ red/2; HIV negative $=$ black/1). Log-rank test for equality of survivor functions. Chi2 (1) $=6.32, \mathrm{P} \mathrm{r}>$ chi2 $=0.0120$

more probability of death (88\%) within the first year period after initiation of lymphoma chemotherapy as observed from the Kaplan Meier graph [Fig. 1]. Only 2/ 40(5.0\%) patients were lost to follow-up in this study, thus was not statistically significant.

The significant difference $(p=0.03)$ in the probability of survival observed between the HIV-infected and HIVuninfected lymphoma groups in this study was similar to studies reported in the USA and Africa but contrary to studies from Europe which showed probability of survival in the HIV-infected group equating that in the HIVuninfected group [23-27, 31-33]. Regional variation in the demographics of these populations, different treatment modalities and variability in the biology of lymphoma sub-types could account for this difference. The difference in probability of mortality between the two groups becomes wider after two years follow-up in this study likely because of high tumor recurrence in the HIV group (not measured in this study) coupled with increased financial burden in these patients with inability to cope with high cost of drugs as duration of follow up increases.

Management of this sub-population should therefore be geared towards early detection of disease and early institution of both chemotherapy and ART. Chemotherapy and other support drugs should be made available and affordable for patients to access easily. The current health insurance program in Nigeria should be expanded to cover cost of chemotherapeutic agents so as to reduce mortality in these patients. Government should as a minimum, upgrade certain hospitals in the country into a status of "centers of excellence for cancer care" equipped with sophisticated equipment for cancer diagnosis and treatment.

Limitations of this study includes use of secondary observational data, small cohort size, lack of information on actual treatment costs and inability to collect other outcome information such as presence of recurrence of lymphoma which might explain survival differences.

Despite these limitations, our study has several strengths. To our knowledge, this is the first study to determine mortality outcomes of HIV-lymphoma in our sub-region and to identify likely contributory factors. Results of this study could serve as initial findings for replication in other regions of the country and could stimulate future larger prospective studies as we continue to unravel the biology of lymphomas associated with HIV infected patients in the current ART era.

\section{Conclusion}

Our findings suggest that HIV infection negatively impacts mortality after lymphoma diagnosis with stage at presentation being a significant determinant of survival in Jos, Nigeria. HIV-associated lymphoma in the ART era continues to contribute to morbidity and high mortality due to increased incidence, biologic heterogeneity and underlying virologic/immunologic factors. With unprecedented improvement in access to ART courtesy of the US President's Emergency Plan for AIDS relief (PEPFAR) project in Nigeria, improved immunity has resulted in an aging HIV population. Future research should be done to better understand the biology of this highly heterogeneous tumor. The research should also be to identify key unique risk factors in this sub-population with renewed emphasis on individualized management to reduce mortality.

\section{Appendix}

\section{A. Ann Arbor staging}

Stage I indicates that the cancer is located in a single region, usually one lymph node and the surrounding area. Stage I often will not have outward symptoms.

Stage II indicates that the cancer is located in two separate regions, an affected lymph node or organ and a second affected area, and that both affected areas are confined to one side of the diaphragm - that is, both are above the diaphragm, or both are below the diaphragm.

Stage III indicates that the cancer has spread to both sides of the diaphragm, including one organ or area near the lymph nodes or the spleen.

Stage IV indicates diffuse or disseminated involvement of one or more extra-lymphatic organs, including any involvement of the liver, bone marrow, or nodular involvement of the lungs.

\section{Modifier}

A or B: the absence of constitutional (B-type) symptoms is denoted by adding an " $\mathrm{A}$ " to the stage; the presence is denoted by adding a "B" to the stage.

$\mathrm{S}$ : is used if the disease has spread to the spleen. 
E: is used if the disease is "extra nodal" (not in the lymph nodes) or has spread from lymph nodes to adjacent tissue.

$\mathrm{X}$ : is used if the largest deposit is $>10 \mathrm{~cm}$ large ("bulky disease"), or whether the mediastinum is wider than $1 / 3$ of the chest on a chest X- ray.

\section{B. W.H.O. classification of lymphoma (2008) Hodgkin.}

Non-Hodgkin (mature B-cell, mature T-cell, NK-cell).

\section{Acknowledgement}

I are greatly indebted to my mentors Dr. Elisa Gordon and Dr. CharlesnikaEvans who thought and supervised me on this project. My special thanks to Dr. Megan McHugh, Emily Rae Mc Elroy and Prof. Jane L. Holl who gave me useful guidance. Also staffs of JUTH, Jos and Center for Global Health, Chicago for all their support. Data and consent gotten from JUTH, Harvard School of Public Health and IRB from NU is also highly appreciated.

\section{Funding}

This work and publication was supported by National Institute of Health (NIH) Fogarty "Northwestern and Jos University Research Training Program in HIV and Malignancies" grant (D43TW009575). Its contents are solely the responsibility of the authors and do not necessarily represent the official views of NIH Fogarty International Center.

\section{Availability of data and materials}

The data that support the findings of this study are available from [Jos University Teaching Hospital Jos, Nigeria and Harvard School of Public Health, USA] but restrictions apply to the availability of these data, which were used under license for the current study, and so are not publicly available. Data are however available from the authors upon reasonable request and with permission of [Jos University Teaching Hospital Jos, Nigeria and Harvard School of Public Health, USA].

\section{Authors' contributions}

OAS, CJA, JOE, OOA, PEA, BMM conceptualized the study and collected data. CJA, RLM, JOE, SAS and LH made technical input in the conceptualization and design of the study. OAS conducted the data analysis, and produced the first draft of the manuscript. CJA, EDJ, MOA, AMD, JM, ANM and JOE contributed in further data analysis, interpretation of findings and editing of the final draft of the manuscript. All co-authors contributed in revising the manuscript and approved the final version for submission.

\section{Competing interests}

The authors declare that they have no competing interests.

\section{Consent for publication}

Not Applicable.

\section{Ethics approval and consent to participate}

This study was approved by Institutional Health Research Ethical Committee of the Jos University Teaching Hospital, Jos (Ref: JUTH/DCS/ADM/127/XIX/ 6477), Institutional Review Board of Northwestern University Chicago, USA and Institutional Review Board of Harvard T.H. Chan School of Public Health, USA. No personal identifiers were used, and informed consent was waived as the study involved minimal risk to patients and data were analyzed in aggregate.

\section{Publisher's Note}

Springer Nature remains neutral with regard to jurisdictional claims in published maps and institutional affiliations.

\section{Author details}

${ }^{1}$ Pathology Department, Faculty of Medical Sciences, University of Jos/Jos University Teaching Hospital, Jos, Plateau State, Nigeria. ${ }^{2}$ Feinberg School of Medicine, Department of Medicine, Northwestern University and Center for Global Health, Chicago, Illinois, USA. ${ }^{3}$ Hematology Department Faculty of
Medical Sciences, University of Jos/Jos University Teaching Hospital, Jos, Plateau State, Nigeria. ${ }^{4}$ Department of Obstetrics and Gynecology Faculty of Medical Sciences, University of Jos/Jos University Teaching Hospital, Jos, Plateau State, Nigeria. ${ }^{5}$ Department of Internal Medicine Faculty of Medical Sciences, University of Jos/Jos University Teaching Hospital, Jos, Plateau State, Nigeria. ${ }^{6}$ Department of Family Medicine Faculty of Medical Sciences, University of Jos/Jos University Teaching Hospital, Jos, Plateau State, Nigeria.

Received: 6 March 2017 Accepted: 26 May 2017

Published online: 05 June 2017

\section{References}

1. Avert Global information and advice on HIV and AIDS. 2015. https://www. avert.org/professionals/hiv-around-world/sub-saharan-africa/nigeria. Accessed 7 Jan 2015.

2. UNAIDS Global Summary of the AIDS Epidermic. 2014. http://www.unaids.org/ sites/default/files/media_asset/20150714_epi_core en.pdf. Accessed 7 Jan 2016

3. Huysentruyt LC, McGrath MS. Mechanisms of AIDS-related Lymphoma Pathogenesis. Futur Virol. 2002;7:229-38.

4. Epeldegui M, Vendrame E, Martinez-Maza O. HIV-associated immune dysfunction and viral infection: role in the pathogenesis of AIDS-related lymphoma. Immunol. 2010;48:72-83.

5. Krause J. AIDS-related non-Hodgkin's lymphomas. Microsc. 2005;68(4):168-75

6. Achenbach CJ, Buchanan AL, Cole SR, Hou L, et al. HIV viremia and incidence of non-Hodgkin lymphoma in patients successfully treated with antiretroviral therapy. Clin Infect Dis. 2014;11:1599-606.

7. Yanik EL, Napravnik S, Cole SR, et al. Incidence and timing of cancer in hiv-infected individuals following initiation of combination antiretroviral therapy. Clin Infect Dis. 2013;5:756-64.

8. Salawu L. AIDS -related lymphomas in Nigeria an emerging phenomenon. Infect Agents Cancer. 2010;5:A3.

9. Patel M, Philip V, Fazel F. Human Immunodeficiency virus infection and hodgkin's lymphoma in South Africa: an emerging problem. Adv Hematol. 2011;2011:578163.

10. Uldrick TS, Little RF. How I treat classical Hodgkin lymphoma in patients infected with human immunodeficiency virus. Blood. 2015;8:1226-35.

11. Castillo JJ, Bower M, Bruhlmann J, et al. Prognostic factors for advancedstage human immunodeficiency virus-associated classical Hodgkin lymphoma treated with doxorubicin, bleomycin, vinblastine, and dacarbazine plus combined antiretroviral therapy: a multi-institutional retrospective study. Cancer. 2015;3:423-31.

12. Gopal S, Patel MR. Lymphoma immune reconstitution inflammatory syndrome in the center for AIDS research network of integrated clinical systems chort. HIV/AIDS. 2014;59:279-86.

13. Mwamba PM, Mwanda WO, Busakhala N, Strother RM, Loehrer PJ, Remick SC. AIDS-Related Non-Hodgkin's Lymphoma in Sub-Saharan Africa: Current Status and Realities of Therapeutic Approach. Lymphoma. 2012;2012. doi:10. $1155 / 2012 / 904367$.

14. de Witt P, Maartens DJ, Uldrick TS. Treatment outcomes in AIDS-related diffuse large B-cell lymphoma in the setting roll out of combination antiretroviral therapy in South Africa. J Acquir Immune Defic Syndr. 2013;1:66-73.

15. Engels EA, Pfeiffer RM, Goedert JJ, et al. Trends in cancer risk among people with AIDS in the United States 1980-2002. AIDS. 2006;12:1645-54.

16. Hessol NA, Seaberg EC, Preston-Martin S, et al. Cancer risk among participants in the women's interagency HIV study. J Acquir Immune Defic Syndr. 2004:4:978-85.

17. Patel P, Hanson DL, Sullivan PS, et al. Incidence of types of cancer among HIV-infected persons compared with the general population in the United States, 1992-2003. Ann Intern Med. 2008;10:728-36.

18. Polesel J, Clifford GM, Rickenbach M, et al. Non-Hodgkin lymphoma incidence in the Swiss HIV Cohort Study before and after highly active antiretroviral therapy. AIDS. 2008;2:301-6.

19. Silverberg MJ, Chao C, Leyden WA, et al. HIV infection and the risk of cancers with and without a known infectious cause. AIDS. 2009;17:2337-45.

20. Silverberg MJ, Chao C, Leyden WA, et al. HIV infection, immunodeficiency, viral replication, and the risk of cancer. Cancer Epidemiol Biomark Prev. 2011:12:2551-9.

21. Biggar RJ, Jaffe ES, Goedert JJ, et al. Hodgkin lymphoma and immunodeficiency in persons with HIV/AIDS. Blood. 2006;12:3786-91.

22. Boué F, Gabarre J, Gisselbrecht C, et al. Phase II trial of CHOP plus rituximab in patients with HIV-associated non-Hodgkin's lymphoma. J Clin Oncol. 2006;25:4123-8 
23. Barta SK, Xue X, Wang D, et al. Treatment factors affecting outcomes in HIV-associated non-Hodgkin lymphomas: a pooled analysis of 1546 patients. Blood. 2013;19:3251-62.

24. Barta SK, Xue X, Wang D, et al. A new prognostic score for AIDS-related lymphomas in the rituximab-era. Haematologica. 2014;11:1731-7.

25. Achenbach CJ, Cole SR, Kitahata MM, et al. Mortality after cancer diagnosis in HIV-infected individuals treated with antiretroviral therapy. AIDS. 2011;5:691-700.

26. Gopal S, Patel MR, Yanik EL, et al. Association of early HIV viremia with mortality after HIV-associated lymphoma. AIDS. 2013;15:2365-73.

27. Gopal S, Patel MR, Yanik EL, et al. Temporal trends in presentation and survival for HIV-associated lymphoma in the antiretroviral therapy era. J Natl Cancer Inst. 2013;16:1221-9.

28. Chao C, Xu L, Abrams D, et al. Survival of non-Hodgkin lymphoma patients with and without HIV infection in the era of combined antiretroviral therapy. AIDS. 2010;11:1765-70.

29. Bonnet F, Burty C, Lewden C, et al. Changes in cancer mortality among HIVinfected patients: the Mortalité 2005 Survey. Clin Infect Dis. 2009;5:633-9.

30. Kent EE, Breen Lewis DR, et al. US trends in survival disparities among adolescents and young adults with non-Hodgkin lymphoma. Cancer Causes Control. 2005;26:1153-62.

31. Bateganya MH, Stanaway J, Brentlinger PE, et al. Predictors of survival after a diagnosis of non-Hodgkin's lymphoma in a resource- limited setting: a retrospective study on the impact of HIV infection and its treatment. Acquir Immune Defic Syndr. 2011;56:312-9.

32. Bolarinwa RA, Ndakotsu MA, Oyekunle AA, et al. AIDS-Related Lymphomas in Nigeria. Braz J Infect Dis. 2009;5:359-61.

33. Oluwasola AO, Olaniyi JA, Otegbayo JA, et al. A fifteen-year review of lymphomas in a Nigerian tertiary healthcare center. J Health Popul Nutr. 2011;4:310-6.

\section{Submit your next manuscript to BioMed Central and we will help you at every step:}

- We accept pre-submission inquiries

- Our selector tool helps you to find the most relevant journal

- We provide round the clock customer support

- Convenient online submission

- Thorough peer review

- Inclusion in PubMed and all major indexing services

- Maximum visibility for your research

Submit your manuscript at www.biomedcentral.com/submit

) Biomed Central 